2019-07

\title{
An approach to evaluating the user experience of serious games
}

Moizer, Jonathan

http://hdl.handle.net/10026.1/13702

10.1016/j.compedu.2019.04.006

Computers and Education

Elsevier

All content in PEARL is protected by copyright law. Author manuscripts are made available in accordance with publisher policies. Please cite only the published version using the details provided on the item record or document. In the absence of an open licence (e.g. Creative Commons), permissions for further reuse of content should be sought from the publisher or author. 


\section{An approach to evaluating the user experience of serious games}

Jonathan Moizera, , Jonathan Leana, Elena Dell'Aquilab, Paul Walsh', Alphonsus (Alfie) Keary $^{c}$, Deirdre O'Byrne ${ }^{d}$, Andrea Di Ferdinando ${ }^{e}$, Orazio Miglino ${ }^{e}$, Ralf Friedrich ${ }^{\dagger}$, Roberta Asperges ${ }^{a}$, Luigia Simona Sica ${ }^{\mathrm{e}}$

a Faculty of Business, University of Plymouth, UK

b Department of Political Sciences, University of Naples Federico II, Italy

${ }^{\mathrm{c}}$ Cork Institute of Technology

${ }^{d}$ Adult Continuing Education, University College Cork, Ireland

e Department of Humanistic Studies, University of Naples Federico II, Italy

${ }^{\dagger}$ German Project Solutions

* Corresponding author. Faculty of Business, University of Plymouth, Plymouth, PL4 8AA, UK

E-mail address: jonathan.moizer@plymouth.ac.uk (J.D. Moizer)

Tel: +44 1752585635

Fax: +44 1752585633

\section{ABSTRACT}

The use of serious games to support learning continues to expand across a range of educational and training settings. Hence, a need exists to understand more fully how users experience such games. This study seeks to describe and assess an approach to the evaluation of user-experience applied within the context of a specific serious game developed to address the training needs of people working in social enterprises. Drawing on an extensive literature review, the development of a survey instrument to capture the multi-dimensional nature of user-experience is explained as is the evaluation process employed. Findings from surveys of individuals working in social enterprises are analysed and discussed. The results demonstrate the value of the proposed method of user-experience evaluation. Recommendations for practice and further research are outlined, identifying in particular the importance of qualitative insights in the evaluation process and the need for greater understanding of the interrelationships between the various dimensions and attributes of user-experience in serious games. Keywords:

Serious game, user experience, UX, evaluation 


\section{Introduction}

'Serious Games' came to prominence in Abt's (1970) book of the same name, and are distinguished by their primary aim of educating rather than purely entertaining users. Whilst serious games do typically entertain, they go beyond 'edutainment' in order to achieve a purpose that is more meaningful and centred around training and skills development, education or attitudinal and behavioural change (Ge, 2017). Serious games may feature active role-play where end-users take on the role of a character within a rule-based setting to achieve a particular goal or set of objectives (Sutcliffe, 2002). The growth in adoption of serious games across a diverse range of educational and training contexts (see Boyle, Hainey, Connolly, Gray, Earp \& Ott et al., 2016 for a full review of applications) means that there is an increasing need to understand and evaluate their effectiveness from a user experience perspective.

Although the expression 'user experience' (UX) has its roots in the field of humancomputer interfaces (Law, van Schaik \& Roto, 2014), it has become a pervasive term that has growing application. A commonly accepted definition is provided by the International Standard on Ergonomics of Human System Interaction, as 'a person's perceptions and responses that result from the use or anticipated use of a product, system or service' (DIS, 2009). User experience can be regarded as central to the usability of technology.McCarthy and Wright (2004) describe UX as the subjective relationship between user and application. They argue that it extends beyond the usability of the application and is focused on the outcome that the user gets from interacting with an application while performing a task.

UX is a critical element of computer game development and use, where an effective UX will determine digital game acceptability (Jakubowski, 2015). Indeed game experience (GX) can be considered as a sub-set of UX (Vermeeren, Law, Roto, Obrist, Hoonhout \& Väänänen-Vainio-Mattil, 2010).

Given the increasing application of serious games in education and training, a sound UX can therefore be considered an important determinant of user learning.

Law and Sun (2012) propose a framework identifying the dimensions of UX in the context of adaptive digital educational games. This adopts a multi-dimensional approach to characterise the breadth of UX attributes associated with serious games. 
Their framework comprises of four key dimensions: gaming experience, learning experience, adaptivity and usability.

This framework forms the basis for the current study that seeks to extend and apply their framework as a mechanism to evaluate the UX of serious games. The paper focuses on a serious game named 'S-Cube' which is used as a learning tool to develop the soft skills of individuals working in social enterprises. The game takes the form of an avatar based online role-play. S-Cube utilises a platform called EUTOPIA ${ }^{1}$, which incorporates a 3D graphic tool for Educational Multiplayer Online Role-Play Gaming (EMORPG).

The EUTOPIA platform has previously been used to develop other serious games, such as an online mediation tool for use in community settings affected by conflict (Dell'Aquila, Marocco, Ponticorvo, di Ferdinando, Schembri \& Miglino, 2017). It provides an enhanced gaming platform to facilitate 'soft skills' training where users undertake 'learning by doing' practice through role play using avatars as their characters. The online nature of the platform allows both geographic and resource barriers to training access to be overcome. The S-Cube game seeks to utilise the strengths of the EUTOPIA platform to address a new set of challenges, specifically those faced by social enterprises. The purpose of this paper is to report on and assess an approach to evaluating UX based on evidence collected from game trials undertaken as part of the S-Cube game development process.

This paper is structured as follows. Firstly, we review the literature pertaining to user experience of serious games before outlining the study objectives. Next, we describe the approach adopted to evaluate UX of the S-Cube game, based on Law and Sun's (2012) framework. This is followed by an appraisal of the UX evaluation approach developed. Finally, we conclude the study and make recommendations for further research.

${ }^{1}$ Developed by the Relational Sciences Department of the Università of Naples Federico II - UNINA) 


\section{User experience in serious games}

Even delimiting the literature surrounding UX and serious games to the extended Law and Sun (2012) framework, writing on the subject area is substantive. Each of their proposed dimensions will now be introduced and the nature of the attributes within them discussed. Fidelity is discussed as an additional dimension of UX evaluation given it is a consistent feature of serious games.

\subsection{Gaming experience}

The term gaming experience at the simplest level concerns the player's one-to-one relationship with the game (Calvillo-Gámez, Cairns \& Cox, 2009). It is difficult to describe and measure what a gaming experience is, as it does not comprise of one experience but numerous, although flow, immersion, affect, challenge and skills development appear to be central to gameplay (Hamari, Shernoff, Rowe, Coller, Asbell-Clarke \& Edwards, 2016).

Game challenge is an attribute of gaming experience associated with a player's perceptions of difficulty where their physical and/or cognitive abilities are challenged within a game (Cox, Cairns, Shah, \& Carroll, 2012). Challenge contributes to immersion (Jennett, Cox, Cairns, Dhoparee, Epps, Tijs \& Walton, 2008) and is an antecedent of game flow (Admiraal, Huizenga, Akkerman \& Dam, 2011), which then allows learning to occur (Jin, 2012). A number of authors argue the link between appropriate levels of game challenge and motivating users to engage with a game to learn and develop skills (Charles, Bustard \& Black, 2011; Lomas, Patel, Forlizzi \& Koedinger, 2013).

Law and Sun (2012) identify gaming competence as the ability to perform tasks or take actions in the game successfully. Gaming competence can be linked to a player's self-efficacy through their ability to master and control a game (Garris, Ahlers \& Driskell, 2002). Players can experience anxiety if their skills are not competent to meet the active challenges set within a game or bored if the challenge is too low (Rau, Peng \& Yang, 2006). Competence development and learning within serious gaming environments has been reported in a number of studies (see for example Cook, McAloon, O'Neill \& Beggs, 2012). 
Csíkszentmihályi (1996) developed flow theory as a way of explaining the state of mind of people who are engaged in a goal driven activity that is sufficiently challenging for their skill level. The UX attribute of flow describes a state of total focus on absorption in a goal driven activity where the individual experiences an optimal psychological state (Procci, Singer, Levy \& Bowers, 2012). The flow effect can increase motivation, which in turn can help promote immersive learning (Paras, 2005). Well-designed games are more likely to promote flow (Van Eck, 2006). Several authors have examined links between flow and serious games with mixed results. Hsieh, Lin and Hou (2016) and Hwang, Sung, Hung, Huang and Tsai (2012); both found links between flow, game performance and learning; whilst only Admiraal et al. (2011) found no such relationship.

Immersion is a critical element of gaming experience and has been used interchangeably with the term flow. Immersion is considered a suboptimal and nonextreme state, because it is the precondition of flow (Cheng, She \& Annetta, 2015); with immersion being achieved when players receive a level of psychological and physical satisfaction from the interaction (Yao, 2010). The level of immersion can be key to game enjoyment and is determined by the game characteristics (Brown \& Cairns, 2004). Avatar based games in particular can be highly immersive as objects and environments are created in 3-D (Berns, Gonzalez-Pardo \& Camacho, 2013) and can help people to learn ; although too much immersion in a game can detract from the achievement of learning outcomes (Cheng et al., 2015).

Affect can influence a range of human attributes such as confidence, self-efficacy and attitudes, and can be identified as types of learning outcomes within serious games (Garris et al., 2002). Games can produce emotions through their affective impact on a player or user. Affect is an important feature allowing games to support learning.

Game designers and facilitators seek to avoid any negative affects of using serious games which comprise of negative emotions such as feeling disengaged, sad, bored or anxious for instance (Sabourin \& Lester, 2014).

Positive affect encourages learners to engage willingly in learning activities as well as promote more effective self-regulation of learning within games (Barzilai \& Blau, 2014). A number of studies found a positive affect of serious games on perceptions 
(Riemer \& Schrader, 2015), motivations (Wouters, Van der Spek \& Van Oostendorp, 2009), engagement (Sabourin \& Lester, 2014), and social and emotional functions such as mood and sociability (Robert, König, Amieva, Andrieu, Bremond, \& Bullock et al., 2014).

Tension can be experienced within a game, which can lead to emotions such as excitement or anger and frustration (Sweetser \& Wyeth, 2005). Tension is an antecedent for game engagement (Wiseman, Blanchard \& Lajoie, 2016); but as Jang and Noh (2017) warn, too high a level of arousal can create emotional instability that detracts from the gaming experience.

\subsection{Learning experience}

Learning experience is very much associated with serious game effectiveness (Cook et al., 2012). Games need to provide the players with clear goals to help them concentrate on the gaming tasks, with feedback used to provide an opportunity for learning (Buil, Catalán \& Martínez, 2018). Serious games are defined by clear rules and goals that allow the player to engage with the game and to learn from the experience. Challenge is also a determinant of goal achievability.

Serious games as well as having their own learning goals can be used to underpin the achievement of wider learning goals (Kao, Chiang \& Sun, 2015). Garzotto (2007) qualifies this by advising that the game content should be aligned to the curriculum within which it is embedded and the goals of the education setting where the game is used. Content appropriateness is also a consideration when choosing the type of serious game (Shegog, Brown, Bull, Christensen, Hieftje \& Jozkowski et al., 2015). Peixoto et al. (2014) suggest that content appropriateness is concerned with evaluating the fidelity of the external world that the game represents.

Integration refers to the notion that game activity should promote reflection on the knowledge and skills that the game provides to players (Garzotto, 2007; Law \& Sun, 2012), as well as encouraging integration of knowledge from different areas to support player decision making (Novak, Johnson, Tenenbaum \& Shute, 2016), and develop new knowledge from the game (Wolfe \& Chanin, 1993). 
Feedback received from games allows participants to reflect on experiences to allow knowledge to be created and/or synthesised within the game so that it can then be applied in the real world (Dzeng, Lin \& Wang, 2014). It can be important for learning that game participants receive more immediate feedback (Qian \& Clark, 2016); be it from the game generated ongoing results (Tsai, Tsai \& Lin, 2015) or the instructor (Yang, 2017).

Whilst the term extensibility in simulation gaming is commonly associated with extending a software's development, Garzotto (2007) uses this term to describe how all the elements associated with learning from a game can be brought together to promote knowledge and understanding and skills development. He also suggests that this expression is associated with ensuring that game content supports achievement of learning goals.

Media matching within serious games is an expression used to identify the most appropriate media form to use, such as animation, sound, picture or text within a game (Leow, Lee, Lillian \& Wang, 2010).

\subsection{Adaptivity}

In an educational context, adaptivity enables the tailoring of learning content to suit the background, needs and goals of individual learners (Soflano, Connolly \& Hainey, 2015). Serious games with adaptive features allow the gaming experience to be adjusted to suit the abilities and rate of progress of the learner (Kickmeier-Rust, Hockemeyer, Albert, \& Augustin, 2008) to reflect the cognitive and motivational aspects of the user. Games can be designed to trigger real-time adaptive interventions in response to user actions; for example repeating tasks, increasing or decreasing the level of difficulty and adjusting the pace of game-play. Further, individualised hints and tips can be prompted, based on a learner's actions and progress within a game. Such adaptive interventions aim to move users from their current 'actual competence state' to the 'desired competence state' (Kopeinik, Nussbaumer, Bedek \& Albert, 2012), and hence, represent a useful mechanism for learning and skills development. 


\subsection{Usability}

Law and Sun (2012) identify that methods based on usability have played a major role in the evaluation of UX. Consistent with Järvinen, Heliö and Mäyrä's (2002) notion of functional playability, serious games must above all else be usable if users are to have a positive gaming experience. The characteristics of usability include ease of use of the interface, user control within the gaming environment, the avoidance of errors, and satisfaction with the games interactive features (Hersh \& Leporini, 2012). Various authors have developed heuristics to assist those evaluating or developing games. For instance, Neilsen (1993) provides guidelines on the provision of information, instructions and feedback to users through both use of non-technical language, and facilitating the easy user exit from an unwanted state.

\subsection{Fidelity}

Fidelity in a serious game is associated with the level of realism that the environment provides to the user. High fidelity is seen as important where transfer of knowledge learnt within the game to real world situations is sought (Petridis, Dunwell, Arnab, Protopsaltis, Hendrix \& de Freitas, 2012). Close correspondence between real and virtual space can be a determinant of the learning transfer; but some authors argue that lower fidelity may lead to higher levels of learning through their simplification of reality (Wright-Maley, 2015).

Chen, Kolko, Cuddihy and Medina (2011) argue that the presentation of a game's graphics and audio affects player immersion and engagement. For instance, graphics or audio that is difficult to understand and poor sound quality is likely to distract a player. Dankbaar, Alsma, Jansen, van Merrienboer, van Saase \& Schuit, (2016) warn that the expectation by players for high fidelity game environments can be associated with negative learning transfer. Jarvis and de Frietas (2009) advise that overemphasising visual fidelity can detract from generating learning activities and experiences, and Marchetti and Valente (2015) suggest that high fidelity creates an acceptance of the game by the learner that can restrict creativity and social interaction. Scholtz, Raga and Baxter (2016) use visual appeal as a UX criterion when considering how well a gamified learning environment is received by learners. 
Chen et al. (2011) suggest that the fidelity of a game interface allows players to immerse themselves into a game with acceptance that the game world's rules are real. Research suggests that where players identify with their game character then higher learning can occur (Pacella \& López-Pérez, 2018).

Verisimilitude should be a key aspect of any serious game and should mirror the objective reality of what is being experienced by a player (Ertz, 2016); but achieving full verisimilitude is impossible (Bremson, 2014). Kibbee (1961) suggests that a player's verisimilitude is far more important than the fidelity of a model to the real world. Keys and Wolfe (1990) advise that a serious game should contain enough verisimilitude to allow real-world-like responses by those participating. Alexander, Brunyé, Sidman and Weil (2005) argue that high graphical fidelity is not necessary to teach with; provided that a game's functional fidelity is adequate.

Law and Sun's (2012) framework provides a valuable guide to the dimensions of user experience and attributes that may need to form part of the UX evaluation where serious game development is concerned.

\section{Study context: The S-Cube game}

The S-Cube game provides an environment in which avatar based multi-player roleplay is undertaken both synchronously and remotely. Players adopt characters and the interactions of the characters are structured around pre-designed learning scenarios set within a social enterprise context (Keary, Walsh, Byrne, Moizer, Lean \& Di Ferdinando et al., 2016). The overall goal of the game was to develop the softskills of the target users (social enterprise employees). This was achieved through role-play gaming whereby participants were required to use their communication and influencing skills to secure pledges of sponsorship and practical support for a social enterprise working within the youth training environment. The game is structured such that participants first have time to orientate themselves with an in-game briefing resource (approximately 10 minutes). Each player is provided with information regarding the scenario and their character's social-demographic background, their role and individual goals. They also receive instructions on how to use the various game features. Following game orientation, participants commence game-play with each session lasting around 30-40 minutes. Player interaction occurs within a 3-D graphical 
environment that players can explore through their avatars. Players communicate through a short text messaging function and via para-verbal and non-verbal communication. For example, players are able to control avatar gestures and body movements, to alter the tone of their 'voice' and express emotion using emoticons. SCube learning sessions are tutor facilitated, with a real time messaging facility for communication between tutors and individual players. Tutors also have the capability to intervene whilst the scenario is evolving to ensure that players stay on track to achieve learning goals. Post-play, debriefing and feedback functions are further features of the S-Cube game capability. Debriefing is aided by the ability of the tutor to record playing sessions and bookmark key learning points within the game play for later review and reflection. Typically, each debriefing lasted around 10-15 minutes. Figure 1 provides a user interface view of the game showing the avatar environment alongside the verbal, para-verbal and non-verbal communication options.

\section{INSERT FIGURE 1 ABOUT HERE}

\section{Research objectives and design of the UX evaluation approach}

The objectives of this study are as follows:

- To describe the development of an approach to evaluating UX for an avatar based serious game (S-Cube);

- $\quad$ To assess the UX evaluation approach in practice;

- To draw on the study findings to make recommendations for the evaluation of $U X$ in serious games.

\subsection{Measures}

As explored in the literature review above, for each of the four dimensions of UX (gaming experience, learning experience, adaptivity and usability), Law and Sun (2012) also identify a number of 'attributes'. For example, the attributes of 'Gaming Experience' identified by Law and Sun are 'challenge', 'competence', 'flow', 'immersion', 'affect' and 'tension'. Such attributes were used as a basis for developing measurement items for the S-Cube evaluation approach. In addition, and based on the review of the extant literature on UX and games, an additional dimension of 'Fidelity' was added as an extension to the Law and Sun framework and appropriate attributes were identified. For each attribute across all five dimensions, statements 
were developed to form measurement items for the instrument used to evaluate UX amongst S-Cube users. A five point Likert scale was employed to assess end-users' level of agreement with each statement (where 1 = 'Strongly Agree' and 5 = 'Strongly Disagree'). Table 1 below categorises the survey measurement items used for each dimension of the evaluation framework.

\section{INSERT TABLE 1 ABOUT HERE}

\subsection{Evaluation process}

Having developed a UX evaluation instrument extended from Law and Sun's (2012) framework, a two-cycle trialling and evaluation process was developed in order to beta-test the S-Cube game. The process enabled the game developers to receive UX feedback from a set of end-users. Figure 2 below outlines the process adopted in trialling the game.

\section{INSERT FIGURE 2 ABOUT HERE}

The first stage of the process was a Training Needs Analysis (TNA) to identify the skill and competency areas in need of development within social enterprises. A survey of 134 individuals who had worked in the social enterprise sector was conducted across the UK, Germany and Ireland. Amongst the most significant skills and competencies identified for development were communication and influencing skills, leadership and personal effectiveness. These priority areas then became the focus during the design and development stage of S-Cube (Stage 2). Then, following internal alpha-tested and refinement of the software (Stage 3), beta-testing was carried out with end-users from social enterprises across the UK, Ireland and Germany (Stages 4 and 5). The first trialling cycle comprised of 116 end-users (40 in the UK, 53 in Ireland and 23 in Germany respectively). The trialling was carried out over a period of several weeks supported by trained facilitators who administered trials in an identical way to ensure consistency of UX across locations. For each trial event, a cohort of approximately five participants engaged in the serious game using a softskills orientated online role-play learning scenario. This number of participants was 
chosen as it could bring about the emergence of group dynamics within the online role-play and therefore facilitate effective evaluation of interactions and learning.

After the first cycle of trials, feedback was gathered regarding the UX of end-user participants utilising the UX survey instrument described above. This was administered via a survey immediately after the gaming and debriefing activity was completed. Data from all end-users was collated and analysed and the results formed the basis for adaptions and revisions to the S-Cube game and learning content. In addition, observations from S-Cube facilitators and open questions within the survey added further insight to support the game refinements. Recordings of each online role-play session were made to assist facilitators in their observational evaluation of the S-Cube software trials. Examples of enhancements included improvements to the movement and navigation of characters through the environment; an enhanced messaging interface; addition of sound effects; addition of new emoticons and removal of various bugs.

Once the enhancements to the S-Cube game were made, the second cycle of trialling then followed with the same structure as the first trials, within which 77 endusers (38 in the UK, 26 in Ireland and 13 in Germany) who had also participated in the first cycle re-trialled with the game. Survey data was again collected from end-users using the same UX survey instrument and under the same conditions. By comparing 'pre' and 'post' data across the trial cohorts, an assessment of the impact of enhancements to the game against the UX dimensions was conducted. Following final revisions, S-Cube was ready for release (Stage 6).

\section{Results from application of the UX evaluation framework}

In order to assess the impact of refinements made to the S-Cube serious game through the trialling process, a comparative analysis of results from the UX survey of end users from each of the two trials was undertaken. Table 2 below summarises and compares the mean ratings given by end-users to items pertaining to UX for Trials 1 and 2. 


\section{$5.1 \quad$ Trial 1}

Findings from Trial 1 highlighted a number of areas where participants gave relatively lower ratings for aspects of UX. For instance, concerning the 'usability' dimension, a mean score of 3.12 for the item 'It was easy to move around' indicated a relatively high level of disagreement with the statement. This reflected difficulties that some users had controlling the movement of avatars within the environment. Another aspect of usability highlighted by the Trial 1 results related to gesture and mood functions within the game, whereby participants could change the facial expressions and gestures of avatars. Results indicated that some participants did not find this function useful (mean $=2.95$ ). Other results from Trial 1 highlighted limitations regarding the 'fidelity' dimension of the game. For instance, mean scores relating to the visual appeal of the playing environment (2.87) and the animated characters (2.76) indicated that improvements were needed to the appearance of the game. Finally, an aspect of the 'learning experience' dimension that was highlighted as an area for enhancement concerned the goals of the game. A mean score of 2.85 for the item 'The learning goals of the game were clear' demonstrated that the purpose and objectives of the game needed to be articulated more effectively to participants.

\section{$5.2 \quad$ Trial 2}

The results from Trial 2 showed that for all items, there were positive improvements to the mean scores. To investigate further the impact of game enhancements post Trial 1, $t$-tests were employed to determine whether there was a significant difference in UX between the two trials. The 2-sample $t$-test method was adopted due to the unequal number of responses to the two UX surveys (a total of 100 users completed the trial 1 survey and 76 completed the trial 2 survey).

\section{INSERT TABLE 2 ABOUT HERE}

Overall, the results show a much-improved perception of S-Cube between Trials 1 and 2. The $t$-tests reveal that there were significant differences in UX across 22 of the 32 survey items ( 12 were significant at $p<0.05$ and 10 at $p<0.01$ ).

In relation to 'Gaming Experience', the comparison of means in Table 2 indicates an improved overall perception of S-Cube between the two trials. Trial 2 end-users 
were significantly more inclined to agree that they were 'Able to achieve the goals set in the game' $(t=5.52 ; \mathrm{p}=0.000)$ and that 'The overall experience was positive' $(t=$ 2.90; $p=0.002)$. The measures for 'Challenge' and 'Tension' show a negative $t$-test value after the second trial; this is likely to be due to end-user learning and experience from engagement in the two trials.

In all aspects of 'Learning Experience' measured, there were increased levels of agreement in relation to the item statements between the two trials. This reflects the improvements made to the learning content of the game ahead of Trial 2, including clearer presentation of the goals of the game $(t=5.29 ; p=0.000)$. Further, technical improvements to the game may have allowed users to focus more on the learning aspects of S-Cube during Trial 2. With respect to 'Adaptivity', a significantly more positive perception of the role of tutor interventions in supporting user confidence emerged following the second trial $(t=2.70 ; p=0.004)$. This reflects the enhancements made to the tutor and player guidelines before Trial 2 .

Significant effort was directed at enhancing aspects of the game 'Usability' based on feedback from Trial 1 . This is demonstrated by the significantly improved mean scores across many survey items relating to usability. For example, there were significant increases in the level of agreement with statements such as 'It was easy to move around' $(t=4.98 ; \mathrm{p}=0.000)$ and 'It was easy to interact with other characters' ( $t$ $=3.88 ; p=0.000)$. As with 'Usability', a number of improvements were made to the 'Fidelity' of the game between the trials in order to enhance the appearance of the gaming environment and avatar characters. Once again, this is reflected in the positive improvements in all mean scores for related measures after Trial 2.

In summary, the enhancements made to both the S-Cube game and the related learning content resulted in improved end-user perceptions of UX after Trial 2.

\section{Discussion of the utility of the UX evaluation framework in serious game development}

The recent growth in the use of serious games within educational contexts reinforces the need for effective mechanisms and processes for the evaluation of such learning approaches. The purpose of serious games goes beyond simple 
entertainment; such games seek to achieve specified learning outcomes and aim to develop skills, knowledge, attitudes or behaviours relevant to the subject or topic of interest (Susi, Johannesson \& Backlund, 2007). Thus, a need exists for multidimensional evaluation approaches to capture the different elements of UX associated with playing a serious game. By developing and testing such an approach, adapted and extended from the work of Law and Sun (2012), this paper has sought to contribute to our understanding of how serious game UX can be evaluated effectively.

Results from the study showing positive changes in UX across the two S-Cube trials indicate that the approach used for measuring UX to inform game enhancements has been effective. The dimensions of gaming experience, learning experience, adaptivity, usability and fidelity measured by the survey instrument appear to capture important attributes of UX for serious games, and therefore provide useful information for game developers. Although the focus of this study was on a specific serious game, the process described in Figure 2 is generic and is therefore generalisable across other contexts. Further, whilst some survey items in Table 1 relate to the specific game context of S-Cube, the dimensions and attributes being measured by the survey items can be generically applied across a variety of serious games. Hence, with adaptions to survey items to account for contextual variations, the UX evaluation approach proposed in the study has the potential to be employed across a range of games.

Despite the positive results emerging from the study, some observations on the potential limitations of the approach adopted can be made. First, whilst quantitative measures from the survey facilitated the identification of overall perceptions in relation to individual UX attributes, qualitative feedback from open survey questions and facilitator observation of trials was also needed in order to implement enhancements. For instance, whilst the quantitative survey results from Trial 1 showed a relatively low level of agreement with the statement 'It was easy to move around', it was only by observing the specific problems that users had with moving their avatar characters that developers were able to take appropriate action. So it is by combining the quantitative results from the survey (to flag the most important areas for improvement) with qualitative feedback and observation (to diagnose the exact nature of the issue) that effective enhancements are implemented. 
A second observation is that while it is useful to disaggregate the various attributes of serious game UX, it is also clear that many such attributes are interrelated. For example, by improving aspects of usability, it is likely that other areas of the game will be enhanced - e.g. aspects of the gaming and learning experience along with fidelity. A greater understanding of such interrelationships would facilitate the identification of the most important attributes where games improvements will have the greatest overall impact on UX.

On a more practical level, a final observation relates to the end-user participants within the evaluation process. In this study, Trial 1 end-users also participated in Trial 2 (with a level of drop out). The advantage of this approach is that participants are able to benchmark and can therefore recognise improvements and provide useful feedback regarding whether and how a game has improved. Working with a consistent group of trial participants therefore has practical benefits in terms of recognising where improvements have been made to UX. A possible disadvantage is that familiarity with a game may naturally result in higher UX evaluations against some measures during subsequent trials.

\section{Recommendations and conclusion}

This paper set out to develop and assess an approach to the evaluation of UX in serious games. This entailed developing a literature informed survey instrument and applying this as part of a six-stage evaluation process. An assessment of the results from the evaluation process demonstrate the utility of the survey instrument and the approach adopted. In particular, the multi-dimensional survey scales facilitated a holistic perspective on UX, covering the key elements of gaming experience, learning experience, adaptivity, usability and fidelity. The study therefore contributes to our understanding of UX evaluation in the specific context of serious gaming.

The study has also enabled the identification of a number of recommendations for both practice and further research. Practical recommendations include the need to augment survey-based evaluation scales with qualitative insights gained through observation and interaction with end-users. Whilst measurement and quantification of user perceptions is an important feature of the evaluation process, actions to enhance games also require qualitative insight in order to effectively diagnose and address UX 
issues. Further, serious game practitioners and developers must carefully consider the design of trials based on the specific needs associated with a given game evaluation, and with attention paid to whether participating end-users should take part in each trial.

Future research in this field would usefully apply the evaluation process and UX dimensions and attributes outlined in this study across a range of serious game contexts in order to validate more fully their generalisability. Further evidence from across a number of games and populations is required to confirm the utility of the approach. In addition, using independent populations for the two beta trialling stages would reduce the potential for bias resulting from game familiarity. Further research might also usefully investigate the associations between different UX attributes in the context of serious games. Models that capture the relationships between such attributes would assist developers in targeting those aspects of UX most likely to have the greatest effect on the overall experience of serious game users. Finally, researchers could investigate how the UX evaluation adopted in this study may be extended to incorporate other approaches to evaluation. In particular, recent studies focusing on in-game interactions as a means to assess UX could be incorporated to add further insight. For instance, Game Learning Analytics (Freire et al, 2016) may facilitate the further enhancement of the model by drawing on data generated during play whilst Stealth Assessment (Shute, Wang, Greiff, Zhao \& Moore, 2016) could be employed to enable in-game performance-based assessment to feed into the evaluation process. 


\section{References}

Abt, C. C. (1970). Serious Games. New York: Viking Press.

Admiraal, W., Huizenga, J., Akkerman, S., \& Ten Dam, G. (2011). The concept of flow in collaborative game-based learning. Computers in Human Behavior, 27(3), 1185-1194.

Alexander, A. L., Brunyé, T., Sidman, J., \& Weil, S. A. (2005, December). From gaming to training: a review of studies on fidelity, immersion, presence, and buy-in and their effects on transfer in PC-based simulations and games. In Proceedings of the 2005 Interservice Industry Training, Simulation, and Education Conference (I/ITSEC), Orlando, FL, 1-14.

Barzilai, S., \& Blau, I. (2014). Scaffolding game-based learning: Impact on learning achievements, perceived learning, and game experiences. Computers \& Education, 70, 65-79.

Berns, A., Gonzalez-Pardo, A., \& Camacho, D. (2013). Game-like language learning in 3-D virtual environments. Computers \& Education, 60(1), 210-220.

Boyle, E. A., Hainey, T., Connolly, T. M., Gray, G., Earp, J., Ott, M., Lim, T., Ninaus, M., Ribeiro, C., \& Pereira, J. (2016). An update to the systematic literature review of empirical evidence of the impacts and outcomes of computer games and serious games. Computers \& Education, 94, 178-192.

Bremson, J. (2014). Representing qualitative aspects of vehicle purchase decisionmaking in a simulation game on alternative fuel and vehicle transitions. In S. A. Meijer, \& R. Smeds (Eds.), Frontiers in Gaming Simulation. ISAGA 2013. Lecture Notes in Computer Science, 8264, (pp. 201-205), Cham, Switzerland: Springer.

Brown, E., \& Cairns, P. (2004, April). A grounded investigation of game immersion. In Proceedings of the Conference on Human Factors in Computing Systems (CHI'04), ACM, Vienna, Austria, 1297-1300.

Buil, I., Catalán, S., \& Martínez, E. (2018). Exploring students' flow experiences in business simulation games. Journal of Computer Assisted Learning. 34(2), 183-192.

Calvillo-Gámez, E. H., Cairns, P. \& Cox, A. L. (2009, September). From the gaming experience to the wider user experience. In Proceedings of the $23 \mathrm{rd}$ British $\mathrm{HCl}$ Group Annual Conference on People and Computers: Celebrating People and Technology, British Computer Society, ACM, Cambridge, UK, 520-523.

Charles, T., Bustard, D., \& Black, M. (2011). Experiences of promoting student engagement through game-enhanced learning. In M. Ma, A. Oikonomou, \& L. 
C. Jain (Eds.), Serious games and Edutainment Applications (pp. 425-445).

London: Springer-Verlag.

Chen, M., Kolko, B.E., Cuddihy, E., \& Medina, E. (2011). Modeling but not measuring engagement in computer games. In Proceedings of the 7th International Conference on Games Learning Society (GLS'11), Madison, WI: ETC Press, 55-61.

Cheng, M. T., She, H. C., \&, Annetta, L. A. (2015). Game immersion experience: its hierarchical structure and impact on game-based science learning. Journal of Computer Assisted Learning, 31(3), 232-253.

Cook, N. F., McAloon, T., O'Neill, P., \& Beggs, R. (2012). Impact of a web based interactive simulation game (PULSE) on nursing students' experience and performance in life support training - A pilot study. Nurse Education Today, 32(6), 714-720.

Cox, A., Cairns, P., Shah, P., \& Carroll, M. (2012, May). Not doing but thinking: the role of challenge in the gaming experience. In Proceedings of the SIGCHI Conference on Human Factors in Computing Systems (CHI '12), ACM, Austin, TX, 79-88.

Csíkszentmihályi, M. (1996). Flow and the Psychology of Discovery and Invention. New York: Harper Collins.

Dankbaar, M. E., Alsma, J., Jansen, E. E., van Merrienboer, J. J., van Saase, J. L., \& Schuit, S. C. (2016). An experimental study on the effects of a simulation game on students' clinical cognitive skills and motivation. Advances in Health Sciences Education, 21(3), 505-521.

Dell' Aquila E., Marocco, D., Ponticorvo, M., di Ferdinando, A., Schembri, M., \& Miglino, O. (2017). Eutopia: Transferring Psycho-pedagogical Role Play to the Multiplayer Digital Stage. In Educational Games for Soft-Skills Training in Digital Environments. Advances in Game-Based Learning, (pp.63-88). Cham, Switzerland: Springer.

DIS, I. (2009). 9241-210: 2010. Ergonomics of human system interaction-Part 210: Human-centred design for interactive systems. International Standardization Organization (ISO). Switzerland.

Dzeng, R. J., Lin, K. Y., \& Wang, P. R. (2014). Building a construction procurement negotiation training game model: Learning experiences and outcomes. British Journal of Educational Technology, 45(6), 1115-1135.

Ertz, M. (2016). Objective: Winning or learning? A study of marketing simulation games. International Journal of Marketing Studies, 8(2), 13.-23 
Freire, M., Serrano-Laguna, Á., Iglesias, B. M., Martínez-Ortiz, I., Moreno-Ger, P., \& Fernández-Manjón, B. (2016). Game Learning Analytics: Learning Analytics for Serious Games. In Learning, Design, and Technology, (pp. 1-29). Cham, Switzerland: Springer.

Garris, R., Ahlers, R., \& Driskell, J.E. (2002). Games, motivation, and learning: A research and practice model. Simulation \& Gaming, 33(4), 441-467.

Garzotto F (2007, June). Investigating the educational effectiveness of multiplayer online games for children. In Proceedings of the 6th International Conference on Interaction Design and Children (IDC '07), ACM, Aalborg, DK, 29-36.

Ge, X., \& Ifenthaler, D. (2017). Designing engaging educational games and assessing engagement in game-based learning. In R. Zheng, \& M. K. Gardner, Handbook of Research on Serious Games for Educational Applications, (pp. 253-270). Hershey, PA: IGI Global.

Hamari, J., Shernoff, D. J., Rowe, E., Coller, B., Asbell-Clarke, J., \& Edwards, T. (2016). Challenging games help students learn: An empirical study on engagement, flow and immersion in game-based learning. Computers in Human Behavior, 54, 170-179.

Hersh, M. A., \& Leporini, B. (2012). Accessibility and usability of educational games for disabled students, In C. Gonzalez (Ed.) Student Usability in Educational Software and Games: Improving Experiences, (pp. 1-40), Hershey, PA: IGI Global.

Hsieh, Y.- H., Lin, Y.- C., \& Hou, H.-T. (2016). Exploring the role of flow experience, learning performance and potential behavior clusters in elementary students' game-based learning, Interactive Learning Environments, 24(1), 178-193.

Hwang, G. J., Sung, H. Y., Hung, C. M., Huang, I., \& Tsai, C. C. (2012). Development of a personalized educational computer game based on students' learning styles. Educational Technology Research and Development, 60(4), 623-638.

Jakubowski, M. (2015). User experience as a crucial element of future simulation and gaming design. Developments in Business Simulation and Experiential Learning, 42, 102-108.

Jang, H. J., \& Noh, G. Y. (2017). The effects of identification with a game character in a smoking simulation game on perceived health risk and smoking attitude. Advanced Science Letters, 23(3), 1673-1676.

Järvinen, A., Heliö, S., \& Mäyrä, F. (2002). Communication and Community in Digital Entertainment Services. Prestudy Research Report, University of Tampere Hypermedia Laboratory [Retrieved from 
http://www.arts.rpi.edu/public_html/ruiz/EGDFall2015/readings/Creating\%20co mmunityUniv.of\%20Tampere.pdf].

Jarvis, S., \& de Freitas, S. (2009). Evaluation of an immersive learning programme to support triage training. In Proceedings of the 1st IEEE International Conference in Games and Virtual Worlds for Serious Applications, IEEE Computer Society, Coventry, UK: 117-122.

Jennett, C., Cox, A. L., Cairns, P., Dhoparee, S., Epps, A., Tijs, T., \& Walton, A. (2008). Measuring and defining the experience of immersion in games. International Journal of Human-Computer Studies, 66(9), 641-661.

Jin, S. A. A. (2012). "Toward integrative models of flow": Effects of performance, skill, challenge, playfulness, and presence on flow in video games. Journal of Broadcasting \& Electronic Media, 56(2), 169-186.

Kao G. Y. - M., Chiang C. - H., \& Sun, C. - T. (2015, July). Designing an educational game with customized scaffolds for learning physics. In Proceedings of the IIAI International Congress on Advanced Applied Informatics 2015, (IIAI AAI 2015), Okayama, Japan, 303-306.

Keary, A., Walsh, P., Byrne, D., Moizer, J., Lean, J., Di Ferdinando, A., Miglino, O., Friedrich, R., Asperges, R., \& Thomson, E. (2016). Using online role-playing games for entrepreneurship training. In P. Rooney, \& N. Whitton, Game-based Learning and the Power of Play: Exploring evidence, Challenges and Future Directions, (pp. 49-81), Newcastle, UK, Cambridge Scholars Publishing.

Keys, B., \& Wolfe, J. (1990). The role of management games and simulations in education and research. Journal of Management, 16(2), 307-336.

Kibbee, J. M. (1961). Model building for management games. In A. Newgarden (Ed.). Simulation and Gaming: A Symposium, (pp. 8-15). New York: American Management Association.

Kickmeier-Rust, M. D., Hockemeyer, C., Albert, D., \& Augustin, T. (2008, November). Micro adaptive, non-invasive knowledge assessment in educational games. In Proceedings of 2008 Second IEEE International Conference on Digital Game and Intelligent Toy Enhanced Learning, IEEE. Banff, BC, Canada, 135-137.

Kopeinik, S., Nussbaumer, A., Bedek, M., \& Albert, D. (2012, November). Using CbKST for learning path recommendation in game-based learning. In Proceedings of the 20th International Conference on Computers in Education (ICCE 2012), Singapore, 26-30.

Law, E. L. C., \& Sun, X. (2012). Evaluating user experience of adaptive digital educational games with Activity Theory. International Journal of HumanComputer Studies, 70(7), 478-497. 
Law, E. L., van Schaik, P., \& Roto, V. (2014). Attitudes towards user experience (UX) measurement. International Journal of Human-Computer Studies, 72(6), 526541.

Leow, M. C., Lee, C. S., Lillian, Y. K. W., \& Wang, K. (2010, April). The need for a new game in learning. Computer Games, Multimedia and Allied Technology (CGAT 2010), Singapore Management University (SMU), Singapore, 74-80.

Lomas, D., Patel, K., Forlizzi, J. L., \& Koedinger, K. R. (2013, April). Optimizing challenge in an educational game using large-scale design experiments. In Proceedings of the SIGCHI Conference on Human Factors in Computing Systems, (CHI '13), ACM, Paris, France, 89-98.

Marchetti, E., \& Valente, A. (2015). Learning via game design: From digital to card games and back again. Electronic Journal of E-learning, 13(3), 167-180.

McCarthy, J., \& Wright, P. (2004). Technology as experience. Interactions, 11(5), 4243.

Neilsen, J. (1993). Usability Engineering. San Francisco, CA: Academic Press Inc.

Novak, E., Johnson, T. E., Tenenbaum, G., \& Shute, V. J. (2016). Effects of an instructional gaming characteristic on learning effectiveness, efficiency, and engagement: Using a storyline for teaching basic statistical skills. Interactive Learning Environments, 24(3):523-538.

Pacella, D., \& López-Pérez, B. (2018). Assessing children's interpersonal emotion regulation with virtual agents: The serious game Emodiscovery. Computers \& Education, 123, 1-12.

Paras, B. (2005, June). Game, motivation, and effective learning: An integrated model for educational game design. In Proceedings of DiGRA 2005 Conference: Changing Views - Worlds in Play, Vancouver, BC, Canada.

Peixoto, D. C. C., Resende R. F., \& Pádua C. I. P. S. (2014). Evaluating software engineering simulation games: The UGALCO framework. In Proceedings of the 44 ${ }^{\text {th }}$ Frontiers in Education Conference (FIE'14), IEEE, Madrid, Spain, 1-9.

Petridis, P., Dunwell, I., Arnab, S., Protopsaltis, A., Hendrix, M., \& de Freitas, S. (2012). Game engines selection framework for high-fidelity serious applications. International Journal of Interactive Worlds, 2012, 1-19.

Procci, K., Singer, A. R., Levy, K. R., \& Bowers, C. (2012). Measuring the flow experience of gamers: An evaluation of the DFS-2. Computers in Human Behavior, 28(6), 2306-2312.

Qian, M., \& Clark, K. R. (2016). Game-based learning and 21st century skills: A review of recent research. Computers in Human Behavior, 63, 50-58. 
Rau, P. L. P., Peng, S. Y., \& Yang, C. C. (2006). Time distortion for expert and novice online game players. CyberPsychology \& Behavior, 9(4), 396-403.

Riemer, V., \& Schrader, C. (2015). Learning with quizzes, simulations, and adventures: Students' attitudes, perceptions and intentions to learn with different types of serious games. Computers \& Education, 88,160-168.

Robert, P. H., König, A., Amieva, H., Andrieu, S., Bremond, F., Bullock, R., Ceccaldi, M., Dubois, B., Gauthier, S., Kenigsberg, P. A., Nave, S., \& Orgogozo, J. M., Piano, J., Benoit, M., Touchon, J., Vellas, B., Yesavage, J., \& Manera, V. (2014). Recommendations for the use of serious games in people with Alzheimer's Disease, related disorders and frailty. Frontiers in Aging Neuroscience, 6, 54, 1-13.

Sabourin, J. L., \& Lester, J. C. (2014). Affect and engagement in Game-Based Learning environments. IEEE Transactions on Affective Computing, 5(1), pp.45-56.

Scholtz, B., Raga, L., \& Baxter, G. (2016). Design and evaluation of a "gamified" system for improving career knowledge in computing sciences. The African Journal of Information and Communication, 18, 7-32.

Shegog, R., Brown, K., Bull, S., Christensen, J. L., Hieftje, K., Jozkowski, K. N., \& Ybarra, M. L. (2015). Serious games for sexual health. Games for Health Journal, 4(2), 69-77.

Shute, V. J., Wang, L., Greiff, S., Zhao, W., \& Moore, G. (2016). Measuring problem solving skills via stealth assessment in an engaging video game. Computers in Human Behavior, 63, 106-117.

Soflano, M., Connolly, T. M., \& Hainey, T. (2015). An application of adaptive gamesbased learning based on learning style to teach SQL. Computers \& Education, $86,192-211$.

Sutcliffe, M. (2002). Simulations, games and role-play. In P. Davies (Ed.). The Handbook for Economic Lecturers, (pp. 1-26). Bristol, UK: The Higher Education Academy Education Network, Bristol, UK.

Sweetser, P., \& Wyeth, P. (2005). GameFlow: a model for evaluating player enjoyment. ACM Computers in Entertainment, 3(3), 1-24.

Tsai, Fu-H., Tsai, C.-C., \& Lin, K.-Y. (2015). The evaluation of different gaming modes and feedback types on game-based formative assessment in an online learning environment. Computers \& Education, 81, 259-269.

Van Eck, R. (2006). Digital game-based learning: It's not just the digital natives who are restless. EDUCAUSE Review, 41(2), 16-30. 
Vermeeren, A. P .O. S., Law, E. L-C., Roto, V., Obrist, M., Hoonhout, J., \& Väänänen-Vainio-Mattila, K. (2010). User experience evaluation methods: current state and development needs. In Proceedings of the $6^{\text {th }}$ Nordic Conference on Human-Computer Interaction: Extending Boundaries (NordiCHI), ACM, New York, NY, 521-530.

Wiseman, J., Blanchard, E. G., \& Lajoie, S. (2016). The deteriorating patient smartphone app: Towards serious game design. In S. Bridges, L. K. Chan \& C. E. Hmelo-Silver (Eds.) Educational Technologies in Medical and Health Sciences Education, (pp. 215-234), Dordrecht, Netherlands: Springer.

Wolfe, J., \& Chanin, M. (1993). The integration of functional and strategic management skills in a business game learning environment. Simulation \& Gaming, 24(1), 34-46.

Wouters, P., Van der Spek, E. D., \& Van Oostendorp, H. (2009). Current Practices in Serious Game Research: A Review from a Learning Outcomes Perspective. In T. M. Connolly, M. H. Stansfield, \& L. Boyle (Eds.) Games-based Learning Advancements for Multi-sensory Human Computer Interfaces: Techniques and Effective Practices, (pp. 232-250), Hershey, NJ: IGI Global.

Wright-Maley, C. (2015). Beyond the "Babel problem": Defining simulations for the social studies. The Journal of Social Studies Research, 39(2), 63-77.

Yang, K. H. (2017). Learning behavior and achievement analysis of digital gamebased learning approach integrating mastery learning theory and different feedback models. Interactive Learning Environments, 25:2, 235-248.

Yao, Y. (2010). Exploring the sense of immersion of MMORPG game design. [Retrieved from https://www.divaportal.org/smash/get/diva2:407054/FULLTEXT01.pdf].

\section{Acknowledgement}

"This project has been funded with support from the European Commission, Agreement Number: UK/11/LLP-LdV/TOI-419, Project Number: 2011-1-GB2-LEO0505526. The authors gratefully acknowledge support from all project partners. This publication reflects the views only of the authors, and the Commission cannot be held responsible for any use which may be made of the information contained therein." 


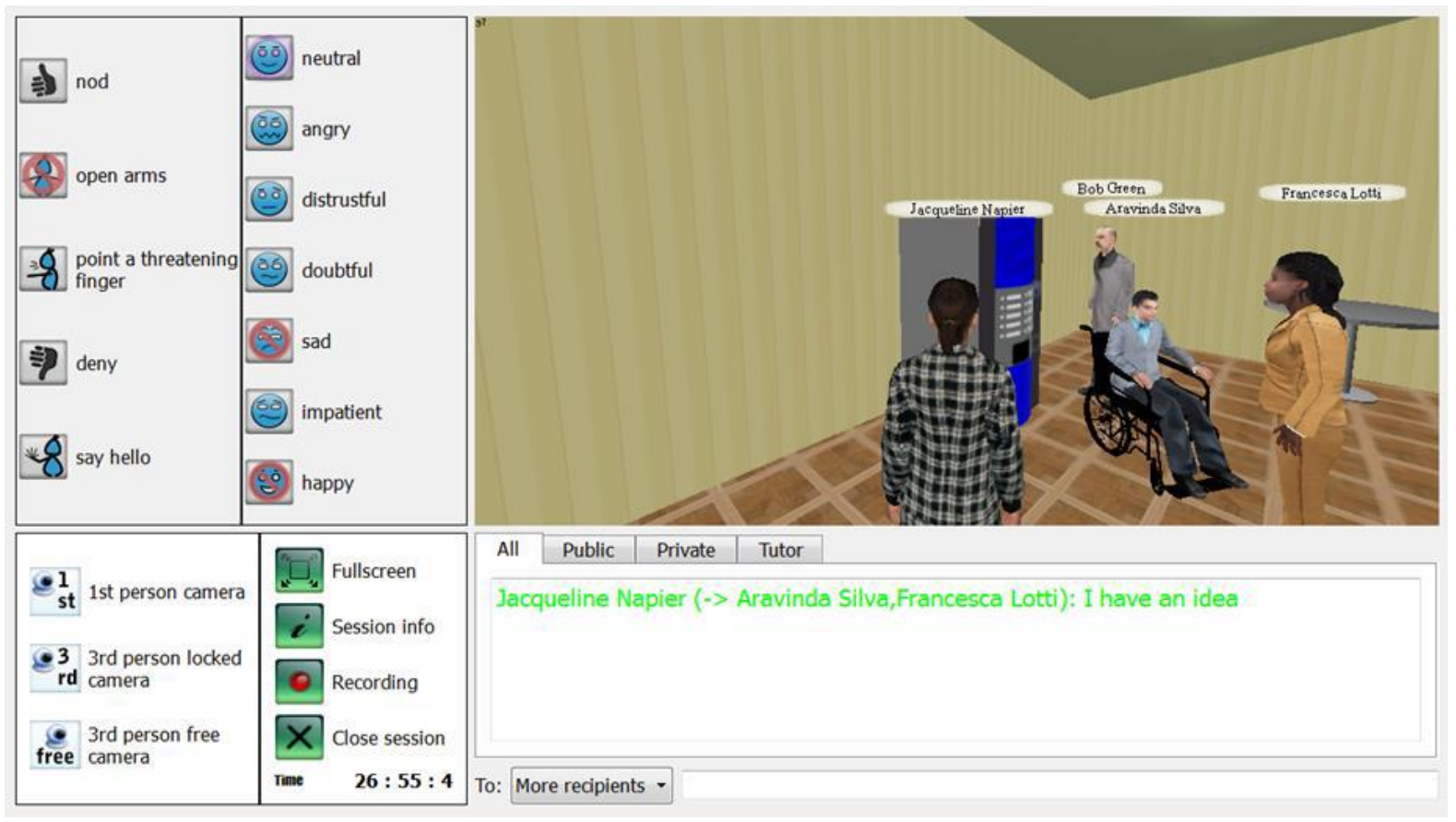

Fig.1. S-Cube player user interface.

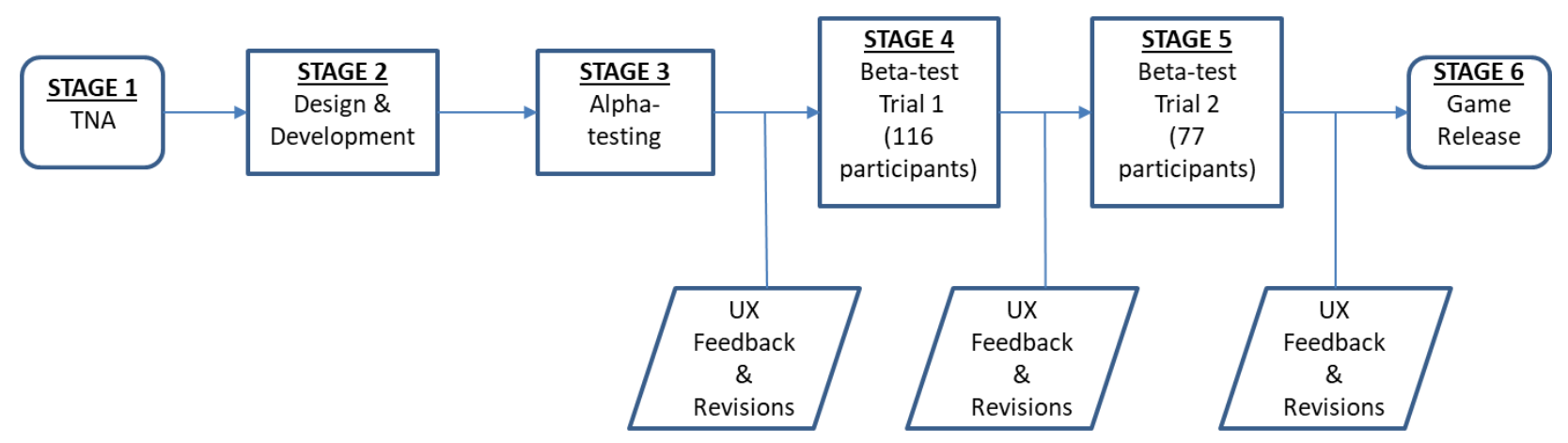

Fig. 2. S-Cube UX evaluation process. 


\section{Table 1}

Survey measurement items.

Dimension Attribute Survey Item

\begin{tabular}{|c|c|c|}
\hline \multirow[t]{6}{*}{$\begin{array}{l}\text { Gaming } \\
\text { Experience }\end{array}$} & Challenge & $\begin{array}{l}\text { The experience was challenging. } \\
\text { I found the game stimulating. }\end{array}$ \\
\hline & Competence & I was able to achieve the goals set in the game. \\
\hline & Flow & I remained focused on the game throughout. \\
\hline & Immersion & The experience was immersive. \\
\hline & Affect & The overall experience was positive. \\
\hline & Tension & Interactions in the game were fraught and tense. \\
\hline \multirow{6}{*}{$\begin{array}{l}\text { Learning } \\
\text { Experience }\end{array}$} & Learning Goal & The learning goals of the game were clear. \\
\hline & $\begin{array}{l}\text { Content } \\
\text { Appropriateness }\end{array}$ & $\begin{array}{l}\text { The game scenario had relevance to the issue of } \\
\text { communication skills development. }\end{array}$ \\
\hline & Integration & $\begin{array}{l}\text { The game required me to use my communication } \\
\text { skills. }\end{array}$ \\
\hline & Feedback & $\begin{array}{l}\text { The game provided opportunities to receive } \\
\text { feedback. }\end{array}$ \\
\hline & Extensibility & $\begin{array}{l}\text { I recognise the value of the game as a tool for } \\
\text { learning. }\end{array}$ \\
\hline & Media Matching & $\begin{array}{l}\text { Using online role play is an appropriate way to } \\
\text { develop communication skills. }\end{array}$ \\
\hline \multirow[t]{3}{*}{ Adaptivity } & $\begin{array}{l}\text { Cognitive \& } \\
\text { Motivational }\end{array}$ & $\begin{array}{l}\text { The tutor interventions were helpful in focusing } \\
\text { my attention. }\end{array}$ \\
\hline & Intervention & $\begin{array}{l}\text { The tutor interventions helped to develop my } \\
\text { confidence. }\end{array}$ \\
\hline & Game Pacing & The pace of the role play was too fast. \\
\hline \multirow[t]{11}{*}{ Usability } & Interface & The user interface was easy to use. \\
\hline & Interaction & It was easy to get started with the software. \\
\hline & & I learnt how to use the software quickly. \\
\hline & & The user manual was well written and clear. \\
\hline & & The survey function aided my reflection. \\
\hline & & The gesture and mood functions were useful. \\
\hline & & It was easy to move around. \\
\hline & & It was easy to create dialogue. \\
\hline & & $\begin{array}{l}\text { It was easy to change character moods and } \\
\text { gestures. }\end{array}$ \\
\hline & & $\begin{array}{l}\text { It was easy to respond to in-game survey } \\
\text { questions. }\end{array}$ \\
\hline & & It was easy to interact with other characters. \\
\hline \multirow[t]{4}{*}{ Fidelity } & Visual Appeal & The playing environment was visually appealing. \\
\hline & & $\begin{array}{l}\text { The animated characters were visually } \\
\text { appealing. }\end{array}$ \\
\hline & Identification & I can identify with the characters in the game. \\
\hline & Verisimilitude & $\begin{array}{l}\text { I can identify with the story/scenario in the game. } \\
\text { The experience felt real. }\end{array}$ \\
\hline
\end{tabular}


Table 2.

Survey mean ratings with $t$-test result between the two trials

\begin{tabular}{|c|c|c|c|c|c|}
\hline Dimension & Attribute & Survey Item & $\begin{array}{l}\text { Trial } \\
\text { Cycle } 1 \\
\text { Mean }\end{array}$ & $\begin{array}{l}\text { Trial } \\
\text { Cycle } 2 \\
\text { Mean }\end{array}$ & $t$ \\
\hline \multirow{7}{*}{$\begin{array}{l}\text { Gaming } \\
\text { Experience }\end{array}$} & Challenge & The experience was challenging. & 2.30 & 2.41 & -0.68 \\
\hline & Competence & I found the game stimulating. & 2.58 & 2.31 & $1.80^{*}$ \\
\hline & Flow & I was able to achieve the goals set in the game. & 3.26 & 2.37 & $5.52^{* *}$ \\
\hline & Immersion & I remained focused on the game throughout. & 2.28 & 2.12 & 1.05 \\
\hline & Affect & The experience was immersive. & 2.35 & 2.07 & $1.89^{*}$ \\
\hline & Tension & The overall experience was positive. & 2.38 & 1.93 & $2.90^{* *}$ \\
\hline & & Interactions in the game were fraught and tense. & 3.06 & 3.43 & $-2.29^{*}$ \\
\hline \multirow{6}{*}{$\begin{array}{l}\text { Learning } \\
\text { Experience }\end{array}$} & Learning Goal & The learning goals of the game were clear. & 2.85 & 2.03 & $5.29^{* *}$ \\
\hline & $\begin{array}{l}\text { Content } \\
\text { Appropriateness }\end{array}$ & $\begin{array}{l}\text { The game scenario had relevance to the issue of } \\
\text { communication skills development. }\end{array}$ & 2.35 & 2.16 & 1.30 \\
\hline & Integration & $\begin{array}{l}\text { The game required me to use my communication } \\
\text { skills. }\end{array}$ & 2.09 & 1.79 & $2.24^{*}$ \\
\hline & Feedback & $\begin{array}{l}\text { The game provided opportunities to receive } \\
\text { feedback. }\end{array}$ & 2.58 & 2.30 & $1.78^{*}$ \\
\hline & Extensibility & $\begin{array}{l}\text { I recognise the value of the game as a tool for } \\
\text { learning. }\end{array}$ & 2.19 & 2.11 & 0.61 \\
\hline & Media Matching & $\begin{array}{l}\text { Using online role play is an appropriate way to } \\
\text { develop communication skills. }\end{array}$ & 2.28 & 2.16 & 0.85 \\
\hline \multirow[t]{3}{*}{ Adaptivity } & $\begin{array}{l}\text { Cognitive \& } \\
\text { Motivational }\end{array}$ & $\begin{array}{l}\text { The tutor interventions were helpful in focusing } \\
\text { my attention. }\end{array}$ & 2.07 & 1.85 & $1.79^{*}$ \\
\hline & Intervention & $\begin{array}{l}\text { The tutor interventions helped to develop my } \\
\text { confidence. }\end{array}$ & 2.62 & 2.23 & $2.70^{* *}$ \\
\hline & Game Pacing & The pace of the role play was too fast. & 2.92 & 2.70 & 1.21 \\
\hline \multirow[t]{11}{*}{ Usability } & Interface & The user interface was easy to use. & 2.33 & 1.85 & $3.39^{* *}$ \\
\hline & Interaction & It was easy to get started with the software. & 2.70 & 2.19 & $3.06^{* *}$ \\
\hline & & I learnt how to use the software quickly. & 2.19 & 1.81 & $2.97^{* *}$ \\
\hline & & The user manual was well written and clear. & 2.74 & 2.12 & $4.09^{* *}$ \\
\hline & & The survey function aided my reflection. & 2.70 & 2.57 & 1.01 \\
\hline & & The gesture and mood functions were useful. & 2.95 & 2.58 & $2.20^{*}$ \\
\hline & & It was easy to move around. & 3.12 & 2.29 & $4.98^{* *}$ \\
\hline & & It was easy to create dialogue. & 2.28 & 2.03 & $1.70^{*}$ \\
\hline & & $\begin{array}{l}\text { It was easy to change character moods and } \\
\text { gestures. }\end{array}$ & 2.32 & 2.00 & $2.05^{\star}$ \\
\hline & & $\begin{array}{l}\text { It was easy to respond to in-game survey } \\
\text { questions. }\end{array}$ & 2.32 & 2.23 & 0.64 \\
\hline & & It was easy to interact with other characters. & 2.49 & 1.93 & $3.88^{* *}$ \\
\hline \multirow[t]{5}{*}{ Fidelity } & Visual Appeal & The playing environment was visually appealing. & 2.87 & 2.49 & $2.24^{*}$ \\
\hline & Identification & $\begin{array}{l}\text { The animated characters were visually } \\
\text { appealing. }\end{array}$ & 2.76 & 2.55 & 1.26 \\
\hline & Verisimilitude & I can identify with the characters in the game. & 2.78 & 2.41 & $2.20^{*}$ \\
\hline & & I can identify with the story/scenario in the game. & 2.47 & 2.31 & 1.04 \\
\hline & & The experience felt real. & 3.09 & 2.73 & $2.14^{*}$ \\
\hline
\end{tabular}

${ }^{*} p<0.05 ; * * p<0.01$ 